\title{
VOLUNTARISMO JUDICIAL Y AUTONOMÍA PARLAMENTARIA (O DE LA JURISPRUDENCIA CONSTITUCIONAL SOBRE LAS FACULTADES DE LAS MESAS PARLAMENTARIAS EN LA CALIFICACIÓN Y ADMISIÓN A TRÁMITE DE PROPUESTAS DE COMPARECENCIA ANTE LAS CÁMARAS O SUS COMISIONES)
}

Parlamentary questions in Constitutional Jurisprudence (About the Constitutional Jurisprudence in respect to the powers of the Parliamentary Boards in the qualification and admission of proposals of appearance before the Chambers or their Commissions)

\author{
PATRICIA RODRÍGUEZ-PATRÓN \\ Universidad Autónoma de Madrid \\ patricia.rodriguez@uam.es
}

Cómo citar/Citation Rodríguez-Patrón, P. (2021)

Voluntarismo judicial y autonomía parlamentaria (o de la jurisprudencia constitucional sobre las facultades de las Mesas parlamentarias en la calificación y admisión a trámite de propuestas de comparencia ante las cámaras o sus comisiones) Anuario Iberoamericano de Justicia Constitucional, 25(1), 171-194. doi: https://doi.org/10.18042/cepc/aijc.25.07

Resumen

En el presente trabajo se analiza la jurisprudencia constitucional sobre las facultades de las Mesas parlamentarias en la calificación y admisión a trámite de propuestas de comparecencia ante las cámaras o sus comisiones. Al hilo de dicho análisis, se 
ponen de manifiesto algunas incoherencias internas de aquella, que hacen vislumbrar, a su vez, un cierto determinismo o voluntarismo judicial que ha jugado casi siempre en contra de la autonomía parlamentaria. Como consecuencia de todo ello, se sugiere en este artículo la necesidad de que el Tribunal Constitucional aborde este tipo de decisiones teniendo en cuenta esa autonomía, dejando a las cámaras el suficiente espacio para su ejercicio, de acuerdo con el criterio de «mínima intervención».

\section{Palabras clave}

Comparecencias; jurisprudencia constitucional; Mesas parlamentarias; trámite de calificación y admisión.

\section{Abstract}

This paper analyzes the constitutional jurisprudence about the powers of the Parliamentary Boards in the qualification and admission of proposals to appear before the Chambers or their Commissions. In line with this analysis, some internal inconsistencies are revealed, which in turn suggest a certain determinism or judicial voluntarism that has almost always played against parliamentary autonomy. As a consequence of all this, the article suggests the need for the Constitutional Court to address this type of decision taking into account that autonomy, leaving the Chambers enough space to exercise it, in accordance with the criterion of «minimal intervention».

\section{Keywords}

Appearances; constitutional jurisprudence; Parliamentary tables; qualification and admission process. 


\section{SUMARIO}

I. INTRODUCCIÓN. II. LA JURISPRUDENCIA CONSTITUCIONAL SOBRE LAS FACULTADES DE CALIFICACIÓN Y ADMISIÓN A TRÁMITE DE LAS PROPUESTAS DE COMPARECENCIA ANTE LAS CÁMARAS O ALGUNAS DE SUS COMISIONES: UNA DOCTRINA DIFÍCILMENTE COMPATIBLE CON LA AUTONOMÍA FUNCIONAL DE LAS CÁMARAS: 1. El criterio general: las Mesas han de limitarse, en principio, a controlar la regularidad formal de las iniciativas presentadas, salvo que la legalidad aplicable establezca algún límite material. 2. Algunas decisiones que contradicen el criterio general: 2.1. Una curiosa excepción: el asombroso caso de la STC 74/2009, de 23 de marzo y su interpretación del art. 162.1 del Reglamento de las Cortes Valencianas. 2.2. La inadmisión de una solicitud de comparecencia por razones materiales contempladas en el reglamento parlamentario. III. UNA OPORTUNIDAD PERDIDA DE RECTIFICAR: EL ATC 47/2018, DE 25 DE ABRIL, DICTADO POR LA SECCIÓN PRIMERA DEL TRIBUNAL CONSTITUCIONAL. IV. VALORACIÓN DE ESTA JURISPRUDENCIA: IMPOSIBILIDAD DE PREDECIR CONFORME A CRITERIOS JURÍDICOS LOS RESULTADOS DE LA FISCALIZACIÓN CONSTITUCIONAL. BibLIOGRAFíA.

\section{INTRODUCCIÓN}

El profesor Francisco Caamaño, en su ponencia «Parlamento. El taller de las verdades fingidas», presentada en el XV Congreso de la Asociación de Constitucionalistas de España celebrado en la Universidad de León en marzo de $2017^{1}$, ponía sobre la mesa, entre otras enjundiosas reflexiones sobre nuestro parlamentarismo actual, la falta de sensibilidad que, una vez superados los años $80^{2}$, ha venido demostrando el Tribunal Constitucional a la hora de resolver los amparos parlamentarios respecto a la autonomía parlamentaria y a la vis política de las Cámaras inherente a la misma. Apuntaba este autor la existencia de un cierto mimetismo respecto a los amparos frente a actos judiciales en los que «casi todas las vulneraciones de derechos se deben a que

Caamaño (2018: 15-54).

2 Como ya habían hecho otros autores, señala como punto de inflexión de dicha progresión la STC 23/1990. 
el acto causante de aquella no ha sido razonable, proporcionado o ha carecido de la debida motivación». Y señalaba, asimismo, que «la reconducción de los derechos al único derecho del art. 23.2 ha hecho que el Tribunal se sumergiese progresivamente "en lo dispuesto en las leyes" - en este caso normas internas de las Cámaras - hasta perder la luz de la Constitución» ${ }^{3}$.

Coincidimos esencialmente con lo afirmado por Caamaño: el Tribunal ha dejado la contención de los primeros años en los que definía su jurisdicción al respecto como de «mínima intervención» ${ }^{4}$, poniendo su mirada principalmente en la normativa parlamentaria y olvidando la posición institucional de autonomía que tienen las cámaras en nuestro ordenamiento.

Pero advertimos algo más: la inmersión en la mera legalidad reglamentaria como método principal de resolver este tipo de amparos, con la consiguiente pérdida de la «luz de la Constitución» a la que se refiere Caamaño, ha llevado a un control de los órganos rectores de las cámaras (en especial, de sus Mesas) aún más férreo que al que se ha sometido a los órganos jurisdiccionales. Pues, como veremos, a diferencia de lo que ha ocurrido respecto a estos últimos, el Tribunal ha llegado a negar en ocasiones la aplicación del canon de la razonabilidad a las decisiones de los órganos parlamentarios ${ }^{5}$, en una clara tendencia a sustituir con su argumentación los criterios de decisión asumidos por estos órganos, que se ven progresivamente constreñidos a la hora de decidir sobre la admisión de las iniciativas parlamentarias que se les presentan ${ }^{6}$.

En este ámbito se ha hecho particularmente evidente, además, algo que con carácter general no se le ha escapado a la doctrina: el notorio componente voluntarista de la jurisprudencia constitucional que se evidencia claramente, en palabras de Ruiz Miguel (2020: 140) en «dos escorzos argumentativos bien familiares [...]: la afirmación de que los precedentes apoyan una nueva tesis que en realidad es palmariamente opuesta a ellos y el reconocimiento de un criterio general que al fin y al cabo resulta escatimado en el caso concreto".

3 Caamaño (2018: 47).

4 Véanse, entre otras, SSTC 14/1990, de 20 de diciembre, FJ 6 y 293/1998, de 4 de mayo, FJ 3. La mención a esa jurisprudencia por el TC no es infrecuente en nuestros días, pero la cita no suele ir acompañada de una contención real. Véase, por ejemplo, STC 20/2018, de 5 de marzo, FJ 3.

5 Es de sobra conocido que el Tribunal detiene su control ante la razonabilidad y no arbitrariedad de las resoluciones judiciales. Entre las más recientes, SSTC 209/2013, de 16 de diciembre, FJ 3; 17/2009, de 26 de enero, FJ 5; 32/2005, de 15 de febrero, FJ 4.

6 Un resumen reciente de la jurisprudencia constitucional sobre la función de las mesas de calificación y admisión de los escritos de índole parlamentaria en general puede encontrarse en De Piniés Ruiz (2019: 409-427). 
Efectivamente, también aquí puede decirse que una cosa es la jurisprudencia sentada con carácter general —que se arrastra de resolución en resolución - y otra muy distinta el modo en el que el Tribunal resuelve cada caso concreto, lo que arroja como resultado la adopción de decisiones radicalmente distintas para casos muy similares, que acercan su fiscalización a un control de oportunidad. Esto hace incurrir al Tribunal en más ocasiones de las deseadas en evidentes contradicciones, al tratar de adaptar su doctrina al resultado que quiere obtenerse en cada caso, lo que impide una razonable $-\mathrm{y}$ exigible — previsibilidad jurídica del resultado del control de la actividad parlamentaria ${ }^{7}$.

A continuación, pondremos algunos ejemplos extraídos de la jurisprudencia constitucional en materia de calificación y admisión a trámite de propuestas de comparecencias ante las cámaras o de sus comisiones, que tratan de ilustrar lo que acabamos de afirmar.

\section{LA JURISPRUDENCIA CONSTITUCIONAL SOBRE LAS FACULTADES DE CALIFICACIÓN Y ADMISIÓN A TRÁMITE DE LAS PROPUESTAS DE COMPARECENCIA ANTE LAS CÁMARAS O ALGUNAS DE SUS COMISIONES: UNA DOCTRINA DIFÍCILMENTE COMPATIBLE CON LA AUTONOMÍA FUNCIONAL DE LAS CÁMARAS}

La necesaria independencia funcional de las cámaras (principalmente, del Congreso y del Senado como órganos constitucionales, pero, por extensión, también de las cámaras legislativas autonómicas) se traduce positivamente en el reconocimiento de su autonomía ${ }^{8}$. O, dicho de otro modo, la autonomía y las potestades de autogobierno que le son inherentes son instrumentos al servicio del óptimo cumplimiento de las funciones de las cámaras, o garantías de su independencia funcional ${ }^{9}$. Solo así es posible el correcto cumplimiento de las competencias que constitucional o estatutariamente se les asignan, a través de las que se manifiesta la particular posición que ocupan en el ordenamiento.

7 Este problema podría enmarcarse en la más amplia cuestión del llamado «constitucionalismo político» que retoma en cierta medida la vieja idea schmittiana acerca de la justicia constitucional. En nuestro país, se ha hecho eco de esta idea López Guerra (2017: 188195), quien advierte del peligro de una indebida influencia del Tribunal Constitucional en el ejercicio de funciones correspondientes a otros poderes del Estado.

8 Romano (1988: 153); Biscaretti Di Ruffia (1987: 349).

9 Véase, en este sentido, Engelmann (1977: 133). Respecto a los órganos constitucionales españoles, Garrorena (1999: 402). 
A su vez, al Tribunal Constitucional, de acuerdo con su doble condición de Tribunal y órgano constitucional, le corresponde respetar en el ejercicio de sus funciones jurisdiccionales esa particular posición de las cámaras, relacionándose con ellas —según expresión de Engelmann (1977: 105 y ss.)— conforme al "principio de comportamiento cordial entre órganos» ("Grundsatz des organfreundlichen Verhaltens»), estando obligado a ser particularmente cuidadoso con los resultados políticos de sus decisiones y con su argumentación.

Es cierto que el TC ha declarado formalmente su respeto a la autonomía parlamentaria, del que se derivaría que «su fiscalización de las decisiones de los órganos de las cámaras ha de limitarse a las decisiones arbitrarias o manifiestamente irrazonables, dejándoles un amplio margen para la decisión». Por ello, ha declarado en ocasiones que «respecto a la función de calificación de los órganos parlamentarios, hay que partir de que este Tribunal solo puede realizar un control negativo, pues no le es dado, por respeto a la autonomía de las cámaras sobre los procedimientos que se desarrollan en su seno, reemplazar la voluntad de sus órganos en el ejercicio de la función de calificación, así como de decisión del procedimiento que han de seguir los escritos parlamentarios» (por todas, SSTC 242/2006, de 24 julio, FJ 2, y STC 68/2020, de 29 de junio, FJ 2).

Pero la realidad de sus resoluciones indica que, pese al respeto proclamado, en demasiadas ocasiones el Tribunal, so capa de permitir únicamente un control formal de las iniciativas por parte de las Mesas, ha terminado sustituyendo con su propio criterio el parecer de estas en la adopción decisiones que no podían considerarse en absoluto «arbitrarias (ni) manifiestamente irrazonables». Esto pone de manifiesto que no siempre hay una concordancia entre el criterio general proclamado y el modo concreto en que el Tribunal resuelve los distintos asuntos que se le presentan, como trataremos de mostrar aquí, al hilo de la jurisprudencia en materia de calificación y admisión a trámite por parte de las Mesas de las propuestas de comparecencia ante las cámaras o algunas de sus comisiones.

\section{EL CRITERIO GENERAL: LAS MESAS HAN DE LIMITARSE, EN PRINCIPIO, A CONTROLAR LA REGULARIDAD FORMAL DE LAS INICIATIVAS PRESENTADAS, SALVO QUE LA LEGALIDAD APLICABLE ESTABLEZCA ALGÚN LÍMITE MATERIAL}

No podemos detenernos en los pormenores de cada una de las decisiones que conforman dicha jurisprudencia, pero, con carácter general, el Tribunal ha aclarado [entre otras, en las SSTC 89 y 90/2005, de 18 de abril, FJ 2 y 208/2003, FJ 4 c)] que las Mesas han de ejercer: 
[...] su función de control de la regularidad legal de los escritos y documentos parlamentarios, sean éstos los dirigidos a ejercer el control de los respectivos ejecutivos, o sean los de carácter legislativo, a la luz del canon normativo del Reglamento parlamentario y sin realizar juicio alguno «sobre la oportunidad política en los casos en que ese juicio esté atribuido a la Cámara parlamentaria» (o a una comisión). Pues, en efecto, el órgano que sirve de instrumento para el ejercicio por los ciudadanos de la soberanía participando en los asuntos públicos por medio de representantes es la Asamblea Legislativa, no sus Mesas, que cumplen la función jurídico-técnica de ordenar y racionalizar el funcionamiento de las Cámaras para su mayor eficiencia, precisamente, como tal foro de debate y participación en la cosa pública.

\section{De este modo, el Tribunal ha establecido que a la Mesa —en principio- únicamente:}

[...] le compete, por estar sujeta al ordenamiento jurídico, en particular a la Constitución, al bloque de la constitucionalidad y a los Reglamentos parlamentarios que regulan sus atribuciones y funcionamiento, y en aras de la mencionada eficacia del trabajo parlamentario, verificar la regularidad jurídica y la viabilidad procesal de las iniciativas, esto es, examinar si las iniciativas cumplen los requisitos formales exigidos por la norma reglamentaria ${ }^{10}$.

Solo en los casos en los que el Reglamento parlamentario permita o, en su caso, establezca, que la Mesa extienda su examen de las iniciativas más allá de la estricta verificación de sus requisitos formales, podrá aquella atender a cuestiones de fondo:

[...] siempre, claro está, que los escritos y documentos girados a la Mesa vengan, justamente, limitados materialmente por la Constitución, el bloque de la constitucionalidad o el Reglamento parlamentario pertinente. De modo que si la legalidad aplicable no impone límite material alguno a la iniciativa, la verificación de su admisibilidad ha de ser siempre formal, cuidando únicamente la Mesa de que la iniciativa en cuestión cumpla con los requisitos de forma que le exige esa legalidad (SSTC 38/1999, FJ 3; 107/2001, FJ 3; 203/2001, FJ 3; 177/2002, FJ 3, y 40/2003, FJ 2) ${ }^{11}$.

Así, solo en los casos en los que la legalidad parlamentaria lo prevea, el TC admite que la Mesa extienda a motivos de fondo su examen de la iniciativa, «como es el caso de la calificación en ciertos Derechos autonómicos de lo que han de considerarse mociones o interpelaciones, o el de la iniciativa legislativa

10 STC 202/2014, de 15 de diciembre, FJ 3 b).

11 Ibid. 
popular que tiene vedadas ciertas materias por imposición del art. 87.3 CE (SSTC 95/1994, 41/1995 y124/1995; ATC 304/1996)»"12.

En el caso concreto de las propuestas de comparecencia ante la cámara o ante una comisión, ha señalado que en la primera fase de calificación y admisión a trámite de estas solicitudes, sólo le correspondería analizar — según la doctrina constitucional citada — «los requisitos de legitimación, así como el ámbito de competencia del requerido, sin que le corresponda rechazar a limine la solicitud de admisión a trámite mediante argumentos de índole material». De otra forma, las resoluciones de rechazo de la Mesa, además de extralimitarse en su función de calificación y admisión realizando un juicio de índole material que le está vedado, contravendrían la legalidad parlamentaria al hurtar a los órganos competentes la facultad de adoptar, en su caso, el acuerdo de requerir la comparecencia, lo que conllevaría también la vulneración del ius in officium del grupo parlamentario proponente ${ }^{13}$.

De acuerdo con todo lo dicho y teniendo presente igualmente el principio de interpretación más favorable a la eficacia de los derechos fundamentales — que ha sido afirmado también en relación con el art. $23.2 \mathrm{CE}^{14}$ _, advierte el TC que la Mesa de la Cámara, al decidir sobre la admisión de este tipo de iniciativas, «no podrá en ningún caso desconocer que son manifestación del ejercicio del derecho del parlamentario que las formula y que, por ello, cualquier rechazo arbitrario o no motivado causará lesión de dicho derecho y, a su través, [...] del fundamental del Diputado a desarrollar sus funciones sin impedimentos ilegítimos (STC 203/2001, de 15 de octubre, FJ 3; que reitera, STC 177/2002, de 14 de octubre, FJ 3)» ${ }^{15}$.

En relación con la motivación exigible a la Mesa a la hora de inadmitir una propuesta de comparecencia, el Tribunal Constitucional ha rechazado que baste con que la decisión adoptada por la Mesa contenga una motivación expresa y razonable, pues ha de «reputarse, además, suficiente y adecuada para la preservación del derecho fundamental» del proponente (art. 23.1 CE), de acuerdo con las normas reglamentarias de aplicación en cada caso ${ }^{16}$. Y no

12 Posteriormente se han pronunciado en el mismo sentido las SSTC 38/1999, de 22 de marzo, FJ 3 b); 107/2001, de 23 de abril, FJ 3 b); 203/2001, de 15 de octubre, FJ 3; 177/2002, de 14 de octubre, FJ 3; 40/2003, de 27 de febrero, FJ 2 b); y 208/2003, de 1 de diciembre, FJ 4 c); y 90/2005, de 18 de abril, FJ 2 c).

13 STC 202/2014, de 15 de diciembre, FJ 4.

14 SSTC 177/2002, FJ 3 y 40/2003, FJ 2.

15 SSTC 203/2001, FJ 3; 177/2002; FJ 3 40/2003, FJ 2; 89/2005, FJ 2 c); 90/2005, FJ 2 c); STC208/2003, FJ 5; 202/2014, de 15 de diciembre, FJ 4.

16 SSTC 38/1999, de 22 de marzo, FJ 2; 107/2001, de 23 de abril, FJ 7; 203/2001, de 15 de octubre, FJ 3; 277/2002, de 14 de octubre, FJ 5; 40/2003, de 27 de febrero, FJ 
considerará esta como tal, incluso aunque no se trate de un control de mera oportunidad, si no se limita a llevar a cabo un «examen de viabilidad formal» de la iniciativa o, más allá de este, «una verificación liminar de la conformidad a Derecho de la pretensión deducida, junto a un juicio de calificación sobre la idoneidad o procedencia del procedimiento parlamentario elegido».

La razón residiría en que la iniciativa supone una mera propuesta a la Comisión correspondiente, en cuya mano está aceptarla o no, por lo que carecería de efectos jurídicos vinculantes en caso de ser aprobada ${ }^{17}$ y, de no atenerse la Mesa a la verificación señalada, estaría «asumiendo bajo un pretendido juicio técnico una decisión política que sólo al Pleno o a las Comisiones de las Cámaras corresponde» ${ }^{18}$.

\section{ALGUNAS DECISIONES QUE CONTRADICEN EL CRITERIO GENERAL}

\section{1. Una curiosa excepción: el asombroso caso de la STC 74/2009, de 23 de marzo, y su interpretación del art. 162.1 del Reglamento de las Cortes Valencianas}

Una curiosa excepción a la doctrina sentada con carácter general la encontramos en un supuesto en el que el propio reglamento parlamentario permitía la inadmisión de la iniciativa por una razón meramente formal, en la que la Mesa se apoya para inadmitir una solicitud de comparecencia. Pese a ello, el Tribunal Constitucional considera que la inadmisión vulnera el ius in officium de los componentes del grupo parlamentario proponente, razón por la cual la anula.

Fue el caso resuelto en la STC 74/2009, de 23 de marzo, en la que se analizó la licitud constitucional de dos resoluciones de la Mesa de las Cortes Valencianas por las que se rechazaba la tramitación de una iniciativa del grupo parlamentario Ezquerra Unida-Els Verds-Entesa Valenciana, por la que se solicitaba la comparecencia del consejero de Territorio y Vivienda ante el Pleno de las Cortes Valencianas, al no haberse obtenido el acuerdo previo de la Junta de Síndics que resultaba preceptivo para la admisión de este tipo de iniciativas, de acuerdo con lo dispuesto en el art. 161 del Reglamento de la cámara autonómica en su redacción entonces vigente, que preveía que la

6; y ATC 188/1999, de 10 de mayo, FJ 5.

17 STC 208/2003, de 1 de diciembre, FFJJ 7-9; en términos parecidos, véanse SSTC 89 y 90/2005, de 18 de abril, FFJJ 3 y 2 c), respectivamente.

18 SSTC 89 y 90/2005, de 18 de abril, FFJJ 7 y 6 , respectivamente. 
comparecencia había de ser aprobada "por acuerdo de la Mesa de las Cortes y de la Junta de Síndics».

En esta sentencia se afirma que dicho rechazo era contrario a los derechos del Grupo Parlamentario recurrente, al no considerarse motivación suficiente del mismo la remisión de la mesa al rechazo de la Junta de Síndics.

En efecto, en el FJ 4 de la citada sentencia se analizan las resoluciones de la Mesa de la Cortes Valencianas de 26 de septiembre de 2005 y 15 de noviembre de 2005, en las que se comunica al grupo parlamentario recurrente que la Junta de Portavoces (Junta de Síndics) de las Cortes Valencianas se había opuesto a la tramitación de la solicitud de comparecencia ante el Pleno de la Cámara del consejero de Territorio y Vivienda instada por uno de sus miembros. Conforme al art. $161 \mathrm{RCV}$ vigente en aquellos momentos, correspondía a los grupos parlamentarios la iniciativa para instar la comparecencia de los miembros del Consejo ante el Pleno de la Cámara. Su admisión requería el acuerdo de la Mesa de las Cortes y la Junta de Síndics y, puesto que el art. 32.1 RCV en vigor reservaba a la Mesa de las Cortes la competencia de «calificar con arreglo a este reglamento los escritos y documentos de índole parlamentaria, así como declarar la admisibilidad o inadmisibilidad de los mismos», en caso de negativa de la Junta de Portavoces correspondía a la Mesa, inevitablemente, declarar la inadmisibilidad de la iniciativa.

Así lo hizo en la resolución impugnada, que se limitó a trasladar el acuerdo de la Junta de Portavoces, con el siguiente tenor literal:

La Junta de Síndics, en la reunión del día 9 de septiembre de 2005, se ha opuesto a la tramitación de la solicitud de comparecencia del Conseller de Territorio y Vivienda para explicar su posición ante la gran proliferación de proyectos urbanísticos presentados en los últimos meses en el País Valenciano y las implicaciones territoriales y ambientales de este proceso, solicitada por el Grupo parlamentario Esquerra Unida-Els Verds-Entesa Valenciana.

Tras plantearse por este la reconsideración, la Mesa confirmó su decisión de «no separarse del criterio fijado por la Junta de Síndics, más aún cuando consultada la Junta sobre el recurso por mayoría de los presentes se manifestó en contra de lo solicitado».

El Tribunal, tras recordar su doctrina acerca de la naturaleza de la facultad parlamentaria de instar la comparecencia de determinadas personas y de su régimen jurídico, su integración en el ius in officium del representante, así como en el núcleo básico de la función parlamentaria garantizado por el art. 23.2 CE (SSTC 177/2002, de 14 de octubre, FJ 5; 208/2003 de 1 de diciembre, FJ 5), llega a la conclusión de que la mera remisión por parte de la Mesa de la Cámara a una decisión inmotivada de rechazo de la Junta de Porta- 
voces no resulta suficiente a los efectos del derecho fundamental garantizado por el art. 23.2 CE. De un lado, porque ello supondría someter a razones de oportunidad política (implícitas en la decisión de la Junta de Síndics) el ejercicio de las facultades de control otorgadas por el Reglamento a los parlamentarios y los grupos en que se integran, y que forman parte del derecho fundamental reconocido en el art. 23 CE. La decisión de la Junta de Síndics, además, tendría carácter interno e irrevisable, lo que se considera inaceptable, pues «en la medida en que un acto parlamentario afecte a un derecho o libertad susceptible de amparo constitucional sale o trasciende de la esfera irrevisable propia de los interna corporis acta y corresponde a este Tribunal el examen, pero sólo ello, de la virtual lesión de derechos o libertades» ${ }^{19}$.

Para el Tribunal:

[...] la resolución de la Mesa, a la vista del carácter imprescindible de la concurrencia del acuerdo de la Junta de Portavoces, podía haberse remitido a la argumentación sobre la inadmisión que hubiera formulado ésta y que podía basarse incluso en cuestiones de organización temporal del trabajo parlamentario (STC 41/1995, de 13 de febrero, FJ 4), pero no al mero resultado decisivo carente en absoluto de motivación. Resulta, por tanto, que en la medida en que en las diversas resoluciones parlamentarias no consta ningún motivo de fondo que justifique la inadmisión de la iniciativa solicitada, constituyen una limitación ilegítima al ejercicio de aquellos derechos y facultades que integran el estatuto constitucionalmente relevante de los representantes políticos (SSTC 40/2003, de 27 de febrero, FJ 6; 242/2006, de 24 de julio, FJ 4) y, en consecuencia, del derecho a ejercer la función parlamentaria (art. 23.2 CE) y [...] el derecho de participación ciudadana en los asuntos públicos (art. 23.1 CE) (las cursivas son nuestras).

Pero si nos detenemos un momento en la decisión de la Mesa, observamos que cumple escrupulosamente con la doctrina sentada con carácter general por el Tribunal: inadmite una solicitud de comparecencia por una razón formal prevista además en el propio Reglamento de la Cámara, sin utilizar, por tanto, argumento material alguno no recogido en el mismo. Por ello sorprende que, precisamente en un caso en el que el Reglamento de la Cámara permite expresamente que la Mesa inadmita la solicitud por una razón meramente formal (en concreto, porque no se ha dado el acuerdo favorable de la Junta de Portavoces), sea cuando el TC exige a la Mesa de forma excepcional que aporte algún motivo material (y no previsto en el Reglamento) para considerar constitucionalmente legítima su inadmisión.

19 Se citan la STC 118/1995, de 17 de julio, FJ 3, y, en el mismo sentido, SSTC 118/1988, de 20 de junio, FJ 2; 227/2004, de 29 de noviembre, FJ 1. 
El respeto al Reglamento por parte de la Mesa se pone de manifiesto en el voto particular que formuló el magistrado Vicente Conde, quien señala que:

No cabe duda de que la Mesa tramitó la solicitud del grupo parlamentario, al dar traslado de la misma a la Junta de Síndics, respetando por lo tanto la facultad de iniciativa, y sólo de iniciativa, que el Reglamento de la Cámara atribuye en su art. 162.1 a los grupos parlamentarios. Denegada la comparencia por la Junta de Síndics, la Mesa trasladó esta decisión como respuesta a la solicitud de comparecencia. Me parece constitucionalmente irreprochable la actuación de la Mesa de la Cámara en atención a la función que reglamentariamente tiene conferida en este caso, pues tramitó la solicitud de comparecencia y trasladó al grupo parlamentario la negativa de la Junta de Síndics a que se acordase la misma, cuya celebración no era ya posible una vez manifestado el parecer desfavorable de la Junta de Síndics, fuera cual fuera ya el parecer de la Mesa de la Cámara, al requerir el Reglamento de la Cámara el acuerdo conjunto de ambos órganos para que se pudiera celebrar la comparecencia solicitada.

Además considera que la sentencia de la que discrepa exige a la Mesa «una fundamentación de las razones por las que se deniega la comparecencia solicitada, que creo que ni le era exigible, ni que ni tan siquiera estuviese a su alcance ${ }^{20}$.

Con ello, se evidencia otro importante problema en relación con el control de constitucionalidad de los actos parlamentarios, cuya complejidad requeriría de un tratamiento en profundidad que no es posible realizar aquí por razones de espacio: si resulta admisible exigir la motivación de las decisiones adoptadas por un órgano parlamentario de carácter político, como es la Junta de Síndics (o la Junta de Portavoces) ${ }^{21}$.

20 Coincide con la visión expresada en el voto particular Duque Villanueva (2009: 286290).

21 La razón de la posición mantenida en este voto particular no es otra que la atención a la naturaleza del órgano llamado a decidir, que en este caso es claramente política, lo cual se argumenta de forma clara. Así, señala Conde: «Creo que constituye error de la Sentencia exigir de la Mesa la fundamentación del acuerdo, que lógicamente no se está refiriendo a lo que correspondía a su función técnica de tramitación de la solicitud de comparecencia, pues la Mesa tramitó la iniciativa parlamentaria, sino a la decisión de la Junta de Síndics de no acordar su celebración, que trasladó al grupo parlamentario autor de la iniciativa, lo que obviamente no estaba al alcance de la Mesa. Tal error, además parte, a su vez, de una exigencia no suficientemente explicitada en la Sentencia, de que la Junta de Síndics, órgano cuyas decisiones en este caso no son de carácter técnico, sino estrictamente político, debiera explicar por su parte las razones para denegar la comparecencia solicitada. Consideración del estricto carácter político de la decisión que es extensible en el supuesto que nos ocupa al peculiar órgano ad hoc que, 
La doctrina sentada en la STC 74/2009, de 23 de marzo, que se ha terminado imponiendo en otras sentencias posteriores en relación a la presentación de propuestas no de ley, cuyo estudio tampoco podremos abordar ahora $^{22}$, resulta sorprendente, además de lo dicho, por otras razones.

En primer lugar, porque es el propio Reglamento - que, ha de recordarse, es manifestación de la autonomía normativa de la cámara y se aprueba por la mayoría absoluta de esta- el que exige que concurra el acuerdo de la Junta de Síndics como condición para la admisión de las solicitudes de comparecencia.

$Y$, en segundo lugar, porque la inclusión de dicha exigencia en el art. 161 RCV se lleva a cabo por las Cortes Valencianas, como no puede ser de otro modo, con pleno conocimiento de la naturaleza de la Junta de Síndics que, como órgano político que es, adopta en nombre de la Cámara por mayoría y mediante el sistema de voto ponderado decisiones políticas que, como diría Aragón Reyes (1986: 16 y 17), se basan en razones igualmente políticas o de oportunidad, que, en cuanto tales, se caracterizan por llevarse a cabo de acuerdo con parámetros subjetivos, no objetivados, disponibles y no necesariamente preexistentes o, dicho de otra manera, se basan, como hemos dicho, en motivos de oportunidad. Sus decisiones son, por tanto, enteramente libres y no se toman por la fuerza del derecho, sino de los votos — como es lo propio de los órganos políticos_, y en ella reside su legitimidad.

Por eso nos asombra particularmente que el Tribunal exigiera a la mesa que indagara sobre la argumentación manejada por la Junta a la hora de adoptar su acuerdo, pues lo único que procedía por parte de aquella, de acuerdo con la propia doctrina constitucional en la materia, era constatar si este era favorable o contrario a la admisión de la solicitud de comparecencia. De acuerdo con esa doctrina, la Mesa viene definida como «órgano de administración y gobierno interion (u «órgano rector») de la cámara, que en el ejercicio de sus facultades de calificación y admisión a trámite realiza principalmente una tarea de carácter técnico-jurídico, debiendo limitarse «al exclusivo examen de los requisitos reglamentariamente establecidos» ${ }^{23}$. Por ello, en nuestra opinión, en esta ocasión cumplió escrupulosamente con sus funciones de calificación

según lo dispuesto en el art. 162.1 del Reglamento aplicable, constituyen la Mesa y la Junta de Síndics».

22 Nos referimos a las SSTC 28/2011, de 14 de marzo; 57/2014, de 6 de octubre; 212/2016, de 15 de diciembre, y 11/2017, de 30 de enero.

23 SSTC 200/2014, de 15 de diciembre, FJ 5; 158/2014, de 6 de octubre, FJ 4; 88/2012, de 5 de junio, FJ 5; 78/2006, de 13 de marzo, FJ 3 b), entre otras. 
de escritos, sin incurrir en ninguna extralimitación, que se habría producido, en cambio, de haber dado curso a la iniciativa sin concurrir el acuerdo de la Junta de Síndics, como exige el Reglamento.

De acuerdo con todo ello, nos parece que el análisis del Tribunal debió consistir en este caso en comprobar si el acuerdo impugnado fue adoptado por los órganos competentes para ello y si, en su proceso de adopción, se cometió alguna irregularidad procedimental o reglamentaria que supusiera, a su vez, una merma de los derechos de los recurrentes en su legítima participación como representantes parlamentarios en la solicitud de comparecencias. Dicha comprobación, en nuestra opinión, hubiera debido conducir, de acuerdo con los argumentos ya ofrecidos, a la desestimación del amparo.

\subsection{La inconstitucionalidad de la inadmisión de una solicitud de comparecencia por razones materiales contempladas en el reglamento parlamentario}

Según hemos visto, el TC ha permitido excepcionalmente a las Mesas inadmitir solicitudes de comparecencia por razones materiales, siempre y cuando estas razones estén previstas en el reglamento o en otra normativa aplicable. Pero no siempre ha aplicado esta doctrina a los casos concretos que ha debido resolver, como ocurrió en la STC 90/2005, de 18 de abril.

a) En esta resolución se resuelve un recurso de amparo interpuesto por el portavoz del Grupo Parlamentario Socialista en el Congreso contra la inadmisión a trámite por la Mesa de su solicitud de comparecencia del fiscal especial anticorrupción, ante la comisión mixta para el estudio del problema de las drogas, para informar sobre las medidas necesarias contra el blanqueo de capitales, al considerar el órgano rector de la cámara que dicha materia resultaba «ajena a las competencias de la referida Fiscalía».

Pese a que el art. 44.3 del Reglamento del Congreso de los Diputados prevé que las comisiones pueden recabar la presencia «de autoridades y funcionarios públicos competentes por razón de la materia objeto del debate, a fin de informar a la Comisión», el TC llega a la conclusión de que la inadmisión de la solicitud de comparecencia vulneró el ius in officium de los diputados que formaban parte del grupo parlamentario recurrente. Porque, a su modo de ver, la Mesa de la cámara no habría «ejercido sus funciones dentro de los límites que enmarcan su potestad de calificación y tramitación de escritos». Es decir, «no llevó a cabo simplemente un "examen de viabilidad formal" de la iniciativa, de acuerdo con los apartados 4 y 5 del art. 31.1 RCD o, más allá de este examen de la viabilidad formal, no procedió exclusivamente a "una verificación liminar de la conformidad a Derecho de la pretensión deducida, junto 
a un juicio de calificación sobre la idoneidad o procedencia del procedimiento parlamentario elegido"».

En definitiva, el Alto Tribunal niega al órgano rector del Congreso la facultad de verificar la "competencia en la materia objeto de debate» de la autoridad cuya presencia se solicita, pese a ser esa competencia un requisito (material) exigido por el art. 44.3 del Reglamento de la Cámara para la solicitud de comparecencias de autoridades y funcionarios públicos. Y, así, aplicando un canon de control estrictamente formal, termina sustituyendo la valoración de la Mesa — que, como se deduce de la propia argumentación del TC podía ser discutible, pero en ningún caso irrazonable o arbitraria ${ }^{24}$ _ por la suya propia, haciendo ceder de esta manera la autonomía funcional de la cámara a favor de unos supuestos derechos de los parlamentarios.

b) Algo parecido ocurrió en la STC 208/2003, de 1 de diciembre. En esta ocasión, el recurrente de amparo solicitó, en su calidad de portavoz del Grupo Parlamentario Socialista del Congreso, la comparecencia del presidente del Consejo General del Poder Judicial ante la Comisión de Justicia e Interior para «informar sobre la posición del Consejo General del Poder Judicial ante el indulto de D. Javier Gómez de Liaño, en los términos en que le ha sido concedido por el Gobierno".

Mediante acuerdo de 5 de diciembre de 2000, la Mesa de la Cámara inadmitió a trámite la solicitud "considerando la materia que constituye el objeto de la presente solicitud en relación con la naturaleza del Consejo General del Poder Judicial como órgano constitucional».

Interesada por el solicitante la reconsideración de la decisión de la Mesa, esta adoptó un nuevo acuerdo denegando la petición con un fundamento similar que concluye con la imposibilidad de fiscalizar las competencias del Consejo como órgano constitucional.

24 Frente a la objeción planteada por el propio Ministerio Fiscal en el proceso de amparo, en cuanto a que el fiscal especial anticorrupción carecía de competencia en la materia que era objeto de la comisión de investigación (tráfico de drogas), opone el TC que «las posibles conexiones que pudieran darse entre estas operaciones y los atribuidos al conocimiento del Fiscal especial anticorrupción no permiten descartar aquella conclusión tajante del Ministerio Fiscal y pensar que, en todo caso, puedan plantearse dudas sobre ello».

Una situación diferente se resolvió en la STC 89/2005, de 18 de abril, pues en aquel caso se solicitó la comparecencia del fiscal especial para la prevención y represión del tráfico ilegal de drogas ante la comisión mixta para el estudio del problema de las drogas, por lo que la denegación de dicha solicitud por parte de la Mesa parecía, a todas luces, irrazonable y arbitraria. 
Al examinar el Tribunal si las razones aducidas por la Mesa para inadmitir la iniciativa parlamentaria que está en el origen del recurso de amparo constituían una motivación "expresa, suficiente y adecuada», advierte de que, conforme a su doctrina, el canon de enjuiciamiento "no es, como sostiene de contrario el Ministerio Fiscal, la apreciación de la razonabilidad de la decisión adoptada por la Mesa del Congreso de los Diputados», sino que ha de atenderse a «las normas a las que (la Mesa) está sujeta en el ejercicio de su función de calificación y admisión de los escritos y documentos de índole parlamentaria (art. 31.1, números 4 y 5, RCD)» (FJ 7).

Contemplados los acuerdos desde esta perspectiva, conviene el Tribunal que los mismos contienen una "motivación expresa» pero esta no resulta «suficiente y adecuada para la preservación del derecho fundamental que nos ocupa». Porque «la decisión de inadmitir la solicitud de comparecencia no se fundamenta, en ninguno de los dos acuerdos de la Mesa de la Cámara, en su inviabilidad formal o en la inidoneidad o improcedencia del procedimiento parlamentario elegido, sino en la ausencia de competencias del Consejo General del Poder Judicial en materia de ejercicio del derecho de gracia y del propio Congreso de los Diputados para exigir responsabilidad política al Presidente del órgano de gobierno del Poder Judicial» (FJ 9). Y ello pese a que, como hemos dicho, el art. 44.3 del Reglamento del Congreso de los Diputados prevé que las Comisiones pueden recabar la presencia «de autoridades y funcionarios públicos competentes por razón de la materia objeto del debate, a fin de informar a la Comisión».

Por otro lado, y frente a lo sostenido por el letrado de las Cortes Generales, señala el Tribunal que no puede descartarse que la petición de comparecencia fuera manifestación del principio de colaboración entre los poderes públicos, pudiendo entenderse «como una solicitud de información para posibilitar, en su caso, el ulterior ejercicio de la función de control del Gobierno, órgano constitucional que otorgó el indulto de referencia».

Es cierto que la doctrina ha mantenido distintas posiciones frente a la solicitud de comparecencias de personas o autoridades no pertenecientes al Gobierno o a la Administración. Así, por ejemplo, Punset Blanco (2013: 4-6) se muestra favorable, en tanto que Astarloa (2011) y Ortega Santiago (2018: 294) no parecen ver con buenos ojos la ampliación del elenco de comparecientes $^{25}$.

25 Este último autor, con carácter más general, ha criticado que el Tribunal Constitucional haya bendecido la admisión a trámite y la viabilidad procedimental de aquellos casos en los que los grupos parlamentarios o sus representantes se sirven de las facultades que les reconoce el Reglamento para ejercer un control e impulso de la acción 
Pero, al margen de cuál sea la valoración que se haga de estas comparecencias, lo que aquí nos interesa resaltar es que la decisión del TC vuelve a sorprender, porque la inadmisión de la Mesa encajaría en uno de los supuestos en los cuales aquel había permitido el rechazo de la iniciativa por razones materiales: cuando estas razones aparezcan contempladas en el Reglamento, en este caso, en el art. 44.1.3 $\mathrm{RC}$, al ser la falta de competencia del Consejo del Poder Judicial en materia de indultos el motivo principal de la inadmisión. Sin negar la razonabilidad de la respuesta dada por la Mesa, la considera lesiva de los derechos de los recurrentes, imponiendo su criterio sobre el expresado por el órgano rector de la cámara.

A mayor abundamiento, la Mesa puso de manifiesto algo que parece evidente: al no pretender la iniciativa, en realidad, que el presidente del Consejo informara sobre ningún asunto en particular, sino que mostrara «la posición» del órgano que presidía sobre el indulto a un exmagistrado, la cámara estaría, en definitiva, fiscalizando al Consejo, lo cual no entra dentro de sus competencias de control que abarca solo a las competencias del Gobierno. De otro lado, no resulta baladí la naturaleza de órgano constitucional del Consejo General del Poder Judicial, cuya autonomía corresponde respetar a los demás órganos constitucionales del Estado, entre otros, al Congreso, como parece apuntar también la decisión de su Mesa. A este respecto, resulta muy significativo que en el FJ 10 de la resolución que ahora comentamos, el TC hace referencia a dos acontecimientos «que impiden adoptar una medida destinada al pleno restablecimiento del derecho vulnerado por la Mesa del Congreso de los Diputados», esto es, que impiden ordenar a esta la admisión de la iniciativa: «la renovación del Consejo General del Poder Judicial y pronunciamiento de la Sentencia del Tribunal de Conflictos de Jurisdicción de 13 de junio de 2001, que delimita las competencias del Gobierno y del Consejo General del Poder Judicial respecto del mencionado indulto y sus efectos». Por esa razón, otorga una eficacia meramente declarativa a su pronunciamiento, limitándose a declarar «la lesión del derecho de los parlamentarios del art. 23.2 CE y la nulidad de los acuerdos que impidieron su ejercicio, que es, justamente, lo que constituye el contenido de la petición deducida en la demanda de amparo».

del gobierno que no les es propia, como habría ocurrido en las SSTC 78/2006, de 13 de marzo, y 29/2011, de 14 de marzo, que resuelven supuestos en los que se pretendía que miembros del Gobierno de la Nación comparezcan en una comisión de investigación de una Asamblea Legislativa autonómica, o que un Parlamento adopte resoluciones con mandatos dirigidos a sujetos políticos no sometidos a su control. 
Tampoco resulta comprensible que el Tribunal niegue la posibilidad de inadmitir por esas razones, si se tiene en cuenta que es competencia de la Mesa la organización del trabajo parlamentario de acuerdo con lo dispuesto en el art. 31 RCD. Para optimizar ese trabajo, resulta plenamente razonable que pueda rechazar las propuestas que no tienen viabilidad o que no se corresponden con las competencias de la Cámara o de sus comisiones.

Por todo lo dicho, no se alcanza a comprender la razón por la cual el Tribunal Constitucional haya de sustituir también aquí el criterio de la Mesa por el suyo propio, salvo que olvide la condición de órgano constitucional autónomo del Congreso.

\section{UNA OPORTUNIDAD PERDIDA DE RECTIFICAR: EL ATC 47/2018, DE 25 DE ABRIL, DICTADO POR LA SECCIÓN PRIMERA DEL TRIBUNAL CONSTITUCIONAL}

El Tribunal tuvo oportunidad de rectificar su doctrina general en materia de calificación y admisión a trámite de las propuestas de comparecencia con la presentación del recurso de amparo 2098-2017 por el Grupo Parlamentario Popular de la Asamblea de Madrid y don Alfonso Serrano Sánchez-Capuchino, oportunidad que dejó pasar con su inadmisión mediante providencia de 24 de enero de 2018.

Los recurrentes denunciaron la inadmisión por la Mesa de la Diputación Permanente de la Asamblea de Madrid de unas solicitudes de comparecencia por falta de relación de los comparecientes con el objeto de la comisión de investigación para la cual se proponían ${ }^{26}$, esto es, por un motivo de fondo no previsto expresamente en el Reglamento de la Cámara. Apoyan sus quejas, precisamente, en la jurisprudencia del Tribunal en la materia, a la que nos hemos referido más arriba, entendiendo legítimamente, conforme a la misma, que la Mesa vulneró su derecho al ejercicio de su cargo parlamentario.

Y de acuerdo con esa jurisprudencia, lo cierto es que la lesión resultaba perfectamente verosímil. Quizá consciente de ello, la sección decidió inadmitir

26 La Mesa de la Diputación Permanente acordó la inadmisión a trámite de las solicitudes de comparecencia ante la «Comisión de Investigación sobre corrupción política en la Comunidad de Madrid» de tres ex altos cargos, que habían sido sucesivamente secretarios de Estado de Comunicación del Gobierno de la Nación entre los años 2005 y 2011. Las resoluciones recurridas se justificaban por la «falta de relación del compareciente con el objeto de la Comisión de Investigación sobre corrupción política en la Comunidad de Madrid». 
el recurso, no por inexistencia de lesión, sino por falta de especial trascendencia constitucional.

Dicha decisión provocó que el Ministerio Fiscal presentara un recurso de súplica, en el que se exponía profusamente la doctrina del Tribunal, de acuerdo con la cual los amparos parlamentarios presentan la dimensión objetiva que está en el fundamento del presupuesto de admisión establecido en el art. 50.1 b) LOTC.

En contestación a dicho recurso, la misma sección dictó el ATC 47/2018, de 25 de abril, en el que, en esencia, rechaza que concurra una especial trascendencia constitucional en el recurso por el mero hecho de que este tuviera unas «consecuencias políticas generales» [letra g) del FJ 2 STC 155/2009, de 25 de junio], al existir doctrina reiterada en materia de propuestas de comparecencias parlamentarias ${ }^{27}$.

27 El criterio mantenido por la sección en este auto respecto a la especial transcendencia constitucional de los amparos parlamentarios, que ha sido objeto de crítica en la literatura jurídica, entre otros, por Miranda López (2019), ha quedado como una pieza aislada dentro de los pronunciamientos en la materia del Alto Tribunal, pues desdecía los pronunciamientos que hasta entonces se habían adoptado e, inmediatamente después, el propio Pleno del TC, en su STC 46/2018, de 26 de abril del Pleno, vuelve a retomar su ya clásica doctrina, de acuerdo con la cual «ha de tenerse en cuenta, por otra parte, que, como han sostenido entre otras muchas las SSTC 10/2018, de 5 febrero, FJ 2, y 27/2018, de 5 de marzo, FJ 2, los amparos de carácter parlamentario (art. 42 de la Ley Orgánica del Tribunal Constitucional: LOTC), como es el que ahora se examina, tienen una particularidad respecto del resto de los recursos de amparo, en cuanto al marco de garantías del que disponen los eventuales recurrentes para invocar sus derechos fundamentales, cual es la ausencia de una vía jurisdiccional previa al amparo constitucional en la que postular la reparación de los derechos vulnerados y que se retrotrae, en origen, a la doctrina de los interna corporis acta, según la cual determinados actos parlamentarios no pueden ser objeto de control por los tribunales ordinarios, circunstancia que ha de conjugarse con el ejercicio del ius in officium por parte de los representantes politicos sin perturbaciones ilegitimas (art. 23.2 CE), y, en última instancia, con el derecho de los propios ciudadanos a participar en los asuntos públicos mediante sus representantes (art. 23.1 CE), lo que sitúa a los amparos parlamentarios en una posición especial a la hora de determinar su dimensión objetiva y valorar la especial trascendencia constitucional por parte de este Tribunal (STC 155/2009, FJ 2), dada la repercusión general que tiene el ejercicio de la función representativa y que excede del ámbito particular del parlamentario y del grupo en el que se integra (STC 200/2014, de 15 de diciembre, FJ 2, entre otras)»(FJ 3). Ni esta, ni otras sentencias posteriores que reiteran este criterio presentan votos particulares que se aparten del mismo, ni siquiera de los tres Magistrados firmantes del ATC 47/2018 (a la sazón, los magistra- 
Pero, en nuestra opinión, este caso brindaba al Tribunal una ocasión de oro para rectificar esa doctrina - lo que habría exigido su admisión a trámite y posterior desestimación-, ofreciendo una visión de las funciones de las Mesas más acorde con su carácter rector de un órgano de las características de las cámaras parlamentarias, así como con las funciones y los procedimientos de estas, en particular de sus comisiones. $\mathrm{O}$, dicho de otro modo, más acorde con la propia lógica del derecho parlamentario. Porque la jurisprudencia existente hasta ahora, como pone en evidencia este caso, puede llevar a la absurda consecuencia de que una Mesa no pueda rechazar una solicitud de comparecencia ante una comisión por no tener relación el compareciente con su objeto. Porque, siempre de acuerdo con esa jurisprudencia, la Mesa estaría hurtando una decisión que corresponde a la comisión misma y efectuando un juicio sobre el fondo que excedería de la comprobación de la viabilidad formal o la idoneidad y procedencia del procedimiento parlamentario elegido y que encerraría un juicio de oportunidad.

Aunque su negativa a entrar en el fondo de la cuestión suponía, respecto del caso concreto, la aceptación de la decisión de la Mesa (y, con ello, un mayor respeto a la autonomía parlamentaria), a su vez significaba la confirmación de la constante jurisprudencia constitucional restrictiva de los poderes de las Mesas para casos venideros, pues la decisión de inadmisión no altera dicha jurisprudencia, de manera que todavía puede servir para la admisión y estimación del amparo en otros casos similares al que aquí se planteaba, en clara contradicción con el principio de igualdad.

Y, de hecho, parece que el TC tiene intención de seguir aplicándola, pues en el FJ 4 de esa resolución se reafirma en lo señalado en ella, admitiendo implícitamente que sería aplicable al caso enjuiciado, de haber concurrido en él una especial trascendencia constitucional:

Las cuestiones jurídicas planteadas por los demandantes, relativas a la competencia de control que los Reglamentos de las Cámaras o Asambleas parlamentarias atribuyen a sus órganos rectores sobre las iniciativas promovidas por los Diputados y Senadores (nacionales o autonómicos), han sido objeto de una abundante, especifica $y$ coherente doctrina expresada en la jurisprudencia constitucional (SSTC 38/1999, de 22 de marzo; 107/2001, de 23 de abril; 177/2002, de 14 de octubre; 208/2003, de 1 de diciembre; 89 y 90/2005, de 18 de abril; 74, 98 y 190/2009, de 23 de marzo, 27 de abril y 28 de septiembre; 33/201 O, de 19 de julio). Su contenido no ha variado desde sus pronunciamientos iniciales (STC 16111988, de 20 de septiembre) y ha sido reiterada más recientemente, tras la reforma de la LOTC por Ley Orgánica 6/2007, en un conjunto de sentencias que se refieren, precisamente,

dos González Rivas, Montoya Melgar y Conde Pumpido, que integraban la Sección Primera del Tribunal). 
a diversas decisiones adoptadas en el seno de la Asamblea de Madrid que fueron cuestionadas en amparo como supuesta muestra de un proceder continuado (SSTC 200/2014; 201/2014 y 202/2014, las tres de 15 de diciembre; 1/2015, de 19 de enero y $23 / 2015$, de 16 de febrero).

A través de dicha doctrina nos hemos pronunciado ya sobre todas las cuestiones jurídicas relevantes planteadas en la presente demanda de amparo; esto es, se han identificado los derechos fundamentales afectados con las decisiones de inadmisión cuestionadas; se ha establecido la relevancia constitucional de aquellos actos que afectan al ius in officium parlamentario, esto es, al núcleo de su función representativa; hemos reconocido la legitimidad de las facultades de verificación y control de la regularidad jurídica y viabilidad procesal de las iniciativas parlamentarias que los Reglamentos de las Cámaras atribuyan a sus órganos rectores; y, en fin, hemos establecido un deber específico de motivar de forma lógica, adecuada y coherente las decisiones de rechazo o inadmisión de las solicitudes formuladas por los miembros de las material.

En conclusión, el caso planteado tampoco permitiría a este Tribunal profundizar, aclarar o complementar su doctrina sobre la cuestión objetiva sometida a su valoración -la capacidad de control de los órganos rectores de las Cámaras parlamentarias- si no, más sencillamente, hacer aplicación concreta de la doctrina reiterada y constante que ha sido expuesta, lo que justifica la desestimación del recurso de súplica formulado (las cursivas son nuestras).

En definitiva, el Tribunal no niega que se hubiera producido una lesión de derechos conforme a su doctrina en la materia y pone de manifiesto que, de haber entrado al fondo de la cuestión, no habría hecho otra cosa que aplicarla, de donde se deduce también que no está por la labor de modificarla o rectificarla, o, al menos, no de forma expresa y con carácter general, pero sí, como se demuestra en este caso, a inaplicarla con carácter puntual por la vía de la inadmisión cuando lo estime oportuno.

\section{VALORACIÓN DE ESTA JURISPRUDENCIA: IMPOSIBILIDAD DE PREDECIR CONFORME A CRITERIOS JURÍDICOS LOS RESULTADOS DE LA FISCALIZACIÓN CONSTITUCIONAL}

Hemos visto que el Tribunal Constitucional ha declarado con carácter general, como no podía ser de otro modo, su respeto a la autonomía de las cámaras, de acuerdo con el cual «no le es dado [...] reemplazar la voluntad de sus órganos en el ejercicio de la función de calificación, así como de decisión del procedimiento que han de seguir los escritos parlamentarios» [entre otras, SSTC 153/2016, de 22 de septiembre, FJ 3; 185/2016, FJ 5 c) y 213/2016, de 15 de diciembre, FJ 4]. En atención a dicha autonomía, ha afirmado en 
ocasiones que, respecto a las decisiones de sus órganos rectores, le corresponde únicamente un control negativo, de manera que su «jurisdicción sólo puede extenderse de manera excepcional y de conformidad con el principio de mínima intervención, para la estricta garantía de los derechos fundamentales de los parlamentarios ${ }^{28}$.

También ha otorgado un papel fundamental en el ejercicio de dicha autonomía a las mesas, por ser estas los órganos de control de la regularidad reglamentaria en la tramitación de las iniciativas parlamentarias y que cumplen «la función jurídico-técnica de ordenar y racionalizar el funcionamiento de las Cámaras para su mayor eficiencia, precisamente como tal foro de debate y participación en la cosa pública $\aleph^{29}$.

Sin embargo, de facto, el Tribunal no ha sido tan respetuoso con las funciones de los órganos rectores de las cámaras ni, por ende, con la autonomía de estas. Porque ha tendido a sustituir las decisiones de sus Mesas incluso cuando no podían considerarse irrazonables ni arbitrarias. Para ello, se ha escudado en una jurisprudencia de apego excesivo a las formalidades del reglamento respectivo, de la que se ha apartado en ocasiones para estrechar aún más el margen de decisión de las Mesas, impidiendo con ello la previsibilidad jurídica del resultado de su control.

Uno de los problemas de estas decisiones es, en nuestra opinión, que atienden exclusivamente a los pretendidos derechos de los parlamentarios sin contemplarlos en el marco que los dota de sentido: las especiales características de las cámaras como órganos constitucionales o estatutarios y las funciones que dentro de ellas han de ejercer sus órganos de gobierno.

Así, no tiene sentido que la Mesa, si ha de ordenar el trabajo de la cámara en aras de la efectividad de su autonomía funcional, no pueda descartar aquellas solicitudes que no resulten adecuadas al objeto de la comisión o que ralenticen u obstaculicen inútilmente sus trabajos, o que se le impida velar por el mantenimiento de unas relaciones respetuosas con la autonomía de otros órganos constitucionales o estatutarios.

En cuanto a la exigencia de una motivación «expresa, suficiente y adecuada» que, en el mejor de los casos, consiste en constreñir a aquella a pronunciarse sobre la viabilidad formal o sobre la idoneidad y procedencia del procedimiento parlamentario elegido, se traduce finalmente en la sustitución de su criterio por el que el Tribunal considera oportuno en cada caso. De este

28 STC 141/2007, de 18 de junio, FJ 4, en relación a los tiempos de intervención en los debates.

29 SSTC 208/2003, de 1 de diciembre, FJ 4; 212/2016, de 15 de diciembre, y 11/2017, de 30 de enero. 
modo, al restringir los poderes del órgano rector de la cámara, el TC amplia correlativamente los suyos, invadiendo la esfera de autonomía propia de las cámaras. A favor de esta última, solo juegan los tiempos de resolución del TC, pues no es infrecuente que su decisión llegue iniciada ya una legislatura distinta a aquella en la que se produjeron los hechos enjuiciados, de modo que no pasa de tener un efecto declarativo ${ }^{30}$.

Por todo lo dicho, consideramos necesaria una nueva doctrina constitucional en la materia más respetuosa con dicha autonomía. Esa doctrina debe estar dotada, además, de mayor coherencia, lo que implica abandonar un cierto voluntarismo que ha dado lugar a la existencia de una jurisprudencia contradictoria de resultados imprevisibles desde el punto de vista jurídico, con el consiguiente perjuicio para los principios de igualdad y de seguridad jurídica $\mathrm{y}$, con ello, para la propia autoridad del Tribunal.

No nos parece el camino adecuado para evitar estos perjuicios la inaplicación puntual de la doctrina actual respecto de casos concretos, como ocurrió, bajo el paraguas de la falta de trascendencia constitucional, con el ATC 47/2018, dictado por la Sección Primera del TC. Porque con ello se tratan de forma diferente casos que merecen ser tratados igual, sin ofrecer ninguna motivación, como correspondería a cualquier cambio de criterio jurisprudencial, dejando a la vez intacta la doctrina acuñada, lista para aplicarse a los casos venideros que el Tribunal estime oportunos.

La corrección propuesta no nos parece imposible, pues en ocasiones el Tribunal Constitucional ha mostrado una mayor contención respecto a la autonomía parlamentaria, como cuando se trata de la ordenación de los debates en la cámara ${ }^{31} \mathrm{o}$, últimamente, respecto a las preguntas parlamentarias ${ }^{32}$.

En definitiva, conviene en nuestra opinión que el TC refleje en sus resoluciones un verdadero respeto a las cámaras como órganos políticos dotados de autonomía frente a los demás órganos (incluyéndole a él mismo), dejándolas el suficiente espacio para su ejercicio y, por tanto, limitando su fiscalización a los casos de decisiones claramente irrazonables y arbitrarias.

30 Así lo ha reconocido el propio Tribunal en alguna de sus decisiones. Así, por ejemplo, en la STC 141/2007 (FJ 6).

Ortega Santiago (2008: 239 y ss.) pone de manifiesto las consecuencias de las sentencias que, por dictarse acabada la legislatura, tienen efectos meramente declarativos.

31 Véanse, a este respecto, las SSTC 214/1990, de 20 de diciembre, FJ 6; 93/1998, de 4 de mayo, FJ 3.

32 STC 68/2020, de 29 de junio, en la que se aclara la doctrina existente hasta entonces en la materia. 


\section{Bibliografía}

Aragón, M. (1986). El control parlamentario como control político. Revista de Derecho Político, (3), 9-39.

Astarloa, I. (2011). Comparecencia ante las Cámaras. En M. Aragón y C. Aguado (dirs.). Temas básicos de Derecho Constitucional. Tomo II (pp. 256-258). Cizur Menor: Civitas.

Biscaretti, P. (1987). Derecho Constitucional. Madrid: Tecnos.

Caamaño, F. (2018). Parlamento. El taller de las verdades fingidas. En M. E. Seija (coord.). Parlamento y Parlamentarismo. Origen y Retos (pp. 15 -54). Valencia: Tirant lo Blanch.

De Piniés, F. J. (2019). Delimitación de la función de calificación de las mesas de las Cámaras. Revista de las Cortes Generales, 533-548. Disponible en: https://doi. org/10.33426/rcg/2019/107/1458.

Duque, J. C. (2009). Doctrina del Tribunal Constitucional durante el primer cuatrimestre de 2009. Organización de los poderes del Estado. Revista Española de Derecho Constitucional, 86, 284-290.

Engelmann, K. (1977). Prozessgrundsätze im Verfassungsprozessrecht. Berlin: Duncker \& Humblot. Disponible en: https://doi.org/10.3790/978-3-428-43850-1.

Garrorena, A. (1999). La reserva del Tribunal Constitucional a Ley Orgánica. En O. Alzaga (dir.). Comentarios a la Constitución Española de 1978. Tomo XII (pp. 389 y ss.). Madrid: Edersa.

López, L. (2017). El Derecho Constitucional en España hoy. En P. Pérez (comp.). El Derecho Constitucional de comienzos del siglo XXI en la Europa Mediterránea. Homenaje a los profesores Luis Favoreu, Alessandro Pizzorusso y Francisco Rubio Llorente (pp. 153-205). Madrid: Centro de Estudios Políticos y Constitucionales.

Miranda, L. (2019). Restricciones a la admisión a trámite de los recursos de amparo parlamentarios. Comentario al auto del tribunal constitucional 47/2018, de 25 de abril, en el recurso de amparo núm. 2098-2017 (BOE, núm. 130, de 29 de mayo de 2018). Revista de las Cortes Generales, 106, 609-617. Disponible en: https://doi.org/10.33426/rcg/2019/106/1414.

Ortega, C. (2008). La natural ultraactividad de las normas parlamentarias sobre la representación. Revista Española de Derecho Constitucional, 82, 319-346.

- (2018). Actualización de los instrumentos de control del parlamento (o de cómo el control parlamentario se adapta a los tiempos y a las circunstancias). Parlamento y Parlamentarismo. Origen y retos. XV Congreso de la Asociación de Constitucionalistas de España (pp. 289-314). Valencia: Tirant lo Blanch,.

Punset Blanco, R. (2013). El control parlamentario en España: cuestiones controvertidas desde la perspectiva de la forma de gobierno. federalismi.it, 11.

Romano, S. (1988). Il Diritto Público Italiano. Milán: Giuffrè.

Ruiz Miguel, A. (2020). Juramento y compromiso parlamentario. Revista de las Cortes Generales, 109, 125-185. Disponible en: https://doi.org/10.33426/ $\mathrm{rcg} / 2020 / 109 / 1528$. 